\title{
COVID-19 Comes 40 Years After AIDS - Any Lesson?
}

\author{
Vicente Soriano ${ }^{1 *}$, Pablo Barreiro², José Manuel Ramos³ ${ }^{3}$ José M. Eirós ${ }^{4}$, and Carmen de Mendoza \\ ${ }^{1}$ UNIR Medical Center and Health Sciences School, UNIR, Madrid; ${ }^{2}$ Infectious Diseases Unit, Carlos III-La Paz University Hospital, Madrid; \\ ${ }^{3}$ University General Hospital, Alicante and Medical School, Miguel Hernández University, Elche; ${ }^{4}$ Rio Hortega University Hospital, Valladolid; \\ ${ }^{5}$ Laboratory of Internal Medicine, Puerta de Hierro University Hospital, Madrid. Spain
}

\begin{abstract}
The pandemic caused by severe acute respiratory syndrome coronavirus 2 (SARS-CoV-2) has hit health-care systems and societies in an unprecedented manner. In 1981, the first cases of AIDS were reported and wide diagnostic testing helped to characterize high-risk groups and the global burden of the epidemic. With Coronavirus Disease (COVID)-19, everything has happened too fast and both cases and fatalities are huge but still uncertain in most places. Diagnostic testing of active and past SARS-CoV-2 infections needs to expand rapidly, ideally using rapid tests. COVID-19 deaths are highly concentrated in the elderly population, with a large proportion of fatalities being "with" rather than "by" SARS-CoV-2 infection. They are often the result of inadequate health care due to overwhelming demands.

To date, there is no specific therapy for SARS-CoV-2 infection. Several antivirals are being tested clinically, including remdesivir, at this time the most promising. For others such as lopinavir/ritonavir, neither significant virological nor clinical benefit has been shown. Given the characteristic pulmonary cytokine storm underlying the pathogenic mechanism of severe COVID-19 pneumonia and acute respiratory distress, antiinflammatory agents are being investigated. The benefit of corticosteroids, hydroxychloroquine, etc., is limited. Monoclonal antibodies targeting different pro-inflammatory cytokines, such as tocilizumab, an anti-interleukin 6 agent, are being tried with encouraging results. Ultimately a protective vaccine will be the best response for controlling the COVID-19 pandemic. (AIDS Rev. 2020;22:63-77)

Corresponding author: Vicente Soriano, vicente.soriano@unir.net
\end{abstract}

\section{Key words}

SARS-CoV-2. HIV. COVID-19. Coronavirus. Antiviral treatment. Transmission. Vaccine. Spain.

\section{Note}

This manuscript has undergone an exceptional internal review process to expedite its dissemination as it dwells upon urgent information of special interest regarding COVID-19.

Correspondence to:

*Vicente Soriano

UNIR Health Sciences School and Medical Center

Calle Almansa 101

Madrid 28046, Spain

E-mail: vicente.soriano@unir.net
Received in original form: 15-04-2020

Accepted in final form: $21-04-2020$

DOI: 10.24875/AIDSRev.M20000030 


\section{Introduction}

An outbreak of pneumonia cases of unknown origin was reported in Wuhan, the capital of the Hubei region, China, in December 2019'. Soon thereafter, a novel enveloped RNA beta-coronavirus was found to be the etiological agent ${ }^{2}$. It was named as severe acute respiratory syndrome coronavirus 2 (SARS-CoV-2), given its close genetic similarity with SARS-CoV, the agent of SARS that in 2002 also had emerged in $\mathrm{China}^{3}$. On January 12, 2020, the World Health Organization (WHO) declared the disease, named COVID-19, a public health emergency of international concern. On March 11, the WHO upgraded COVID-19 as a pandemic.

During the past century, several major epidemics have periodically challenged the world. At the end of World War I, the Spanish influenza killed millions of people and spread worldwide ${ }^{4}$. Since then, other large global viral outbreaks have occurred (Table 1). Alike COVID-19, distinct strains of influenza have caused major pandemics in 1957 (H2N2 Asian flu) or 2009 (H1N1 Swine flu). Although their clinical severity was low, their airborne transmissibility was very efficient, infecting more than 1 billion people and causing hundreds of thousands of fatalities ${ }^{4}$.

Self-limited, acute viral pandemics such as COVID-19 behave totally different from chronic viral pandemics, such as HIV or hepatitis B and C, that depict long incubation periods and spread more restrictively, as following sexual contact and/or blood-borne exposure. Whereas antiviral therapies seem to work the best against chronic viral infections, the greater benefit confronting acute self-limited infections is obtained with vaccines. Table 2 records the main features of major chronic viral epidemics and current weapons to control them ${ }^{5-10}$.

Having attained a significant control of AIDS after estimates approaching 80 million cumulative HIV infections up to date, which lessons could be drawn for confronting the new COVID-19 threat more efficiently ${ }^{11-13}$. Table 3 records the major differences between HIV and SARS-CoV-2.

\section{RNA viruses at front of pandemics}

The spectrum of infectious disease threats has changed as new chemotherapies have been discovered. After World War II, the advent of the first antibiotics penicillin and sulfa drugs dramatically improved outcomes of bacterial infections. Alike, the discovery of streptomycin and isoniazid represented major steps against tuberculosis. Unfortunately, upon control of major bacterial infections, viruses steadily took over as major etiological agents of untreatable infections by the end of the $20^{\text {th }}$ century.

By definition, viruses are parasites. They need the machinery of infected cells to complete their life cycle. The lead motif of any virus is to produce progeny by unit of time. At the population level, this goal can be accomplished strategically by two ways. First, producing high replication of viral particles in a short timeframe within one single infected host, and potentially destroying it. The pay toll for such a strategy is that transmission is timely constricted. A good example is Ebolavirus. A second approach is producing replication of viral particles without compromising significantly the host survival, causing a chronic persistent infection. This strategy provides higher chances for transmission to others and replication in multiple hosts for long periods. The best example is HIV.

Based on the nature of their nucleic acid, viruses can be split out into DNA and RNA viruses. Vaccines have been developed against many pathogenic human DNA viruses, such as hepatitis B or papillomavirus. Indeed, smallpox is the only illness caused by a DNA virus that has been eradicated so far on earth using a vaccine. For RNA viruses, vaccines have also been successfully developed for many agents (hepatitis $A$, rabies, measles, yellow fever, polio, rubella, etc.). However, a vaccine has remained elusive for other RNA viruses such as HIV or hepatitis C, largely due to their wide genetic variability. The error-prone nature of RNA viral polymerases confers an evolutionary advantage to these highly replicating RNA viruses, allowing rapid adaptation to new conditions. Indeed, many RNA viruses exist as quasispecies, meaning that their genetic sequences rapidly evolve and adapt as a cloud around a master sequence, with enrichments or losses depending on new conditions ${ }^{14}$.

\section{Human coronaviruses (HCoVs)}

Coronaviruses are among the largest genome RNA viruses, with roughly 30,000 nt. As a comparison, HIV or hepatitis C virus has around 10,000 nt and influenza only 2300 nt (Fig. 1). Seven HCoVs have been reported so far. All may produce respiratory tract infections. Four typically are associated to seasonal flu-like illnesses and are endemic in most geographical regions. In contrast, three coronaviruses are highly pathogenic and may cause epidemics, including the 
V. Soriano, et al: COVID-19 comes 40 years after AIDS - any lesson?

\begin{tabular}{|c|c|c|c|c|c|c|}
\hline Virus & Year & Cases & Deaths & Fatality rate & Countries affected & Epicenter \\
\hline H3N2 Hong Kong flu & 1968-to date & Pandemic & 1 million & $0.3 \%$ & Worldwide & Hong Kong \\
\hline Marburg & 1967 & 466 & 373 & $80 \%$ & 11 & DR Congo \\
\hline Ebola & 1976 & 602 & 431 & $66 \%$ & 2 & Sudan and Congo \\
\hline Hendra & 1994 & 7 & 4 & $57 \%$ & 1 & Australia \\
\hline H5N1 bird flu & 1997-to date & 861 & 455 & $53 \%$ & 18 & Hong-Kong \\
\hline Nipah & 1998 & 513 & 398 & $78 \%$ & 2 & Malaysia \\
\hline SARS & $2002-2003$ & 8096 & 774 & $9 \%$ & 29 & China \\
\hline H1N1 swine flu & 2009-to date & Pandemic & $>285,000$ & $<0.1 \%$ & Worldwide & Mexico \\
\hline MERS & 2012-to date & 2506 & 861 & $34 \%$ & 28 & Saudi Arabia \\
\hline H7N9 bird flu & 2013 & 1568 & 616 & $39 \%$ & 3 & China \\
\hline Ebola & 2014-2016 & 28,646 & 11,323 & $70 \%$ & 10 & Guinea-Conakry \\
\hline Ebola & 2018-to date & 3456 & 2266 & $65 \%$ & 2 & DR Congo \\
\hline SARS-CoV-2 & 2019-to date & $>4,000,000$ & $>300,000$ & $<1 \%$ & Worldwide & China \\
\hline
\end{tabular}

\begin{tabular}{|c|c|c|c|c|}
\hline Virus & Infected persons & Disease & Major epicenters & Weapons \\
\hline Hepatitis B & 270 million & Cirrhosis and liver cancer & Southeast Asia & Antivirals and vaccines \\
\hline Hepatitis C & 70 million & Cirrhosis and liver cancer & Asia & Antivirals \\
\hline HIV & 38 million & AIDS & Sub-Saharan Africa & Antiretrovirals \\
\hline Hepatitis delta & 60 million & Cirrhosis and liver cancer & $\begin{array}{l}\text { Amazon basin, Sub-Saharan } \\
\text { Africa, Central Asia }\end{array}$ & None \\
\hline HTLV-1 & 10-15 million & $\begin{array}{l}\text { Myelopathy and } \\
\text { Iymphoma }\end{array}$ & $\begin{array}{l}\text { Sub-Saharan Africa and Latin } \\
\text { America }\end{array}$ & None \\
\hline Papillomavirus & 300 million & Cervical cancer & Worldwide & Vaccine \\
\hline
\end{tabular}

new COVID-19 agent (Table 4). Of the human pathogenic coronaviruses, the former 2002 SARS-CoV is the most well known ${ }^{3}$.

The four endemic coronaviruses include HCoV-229E, HCoV-NL63, HCoV-OC43, and HCoV-HKU1. They usually cause self-limiting upper respiratory infections, which account for $15 \%-30 \%$ of common colds. Symptoms are generally mild in young adults but may lead to hospitalization in elderly patients with underlying cardiac or lung diseases. Anyway, typically, coronaviruses account for a small proportion of patients hospitalized for acute respiratory illness each winter ${ }^{15}$. 
AIDS Reviews. 2020;22

Table 3. Major differences between HIV-1 (AIDS) and SARS-CoV-2 (COVID-19) infections

HIV-1

AIDS (immunodeficiency)

Disease

Origin country

Year beginning

Zoonosis

Genome

Mutation rate

Infectivity

Fatality rate

Transmission

Diagnosis

Infected people

Length

Receptor
Cameroon and Gabon

1981

Chimps and gorillas

dsRNA, $10,000 \mathrm{~Kb}$

$4 \times 10^{-3} /$ site/year

Life-long

$>90 \%$ (in the absence of ART)

Parenteral, sexual, vertical

Plasma PCR, blood serology

78 million (49\% alive)

Chronic (lifelong)

CD4 and CCR5/CXCR4 at T lymphocytes
SARS-CoV-2

COVID-19 (pneumonia and respiratory distress)

China

2019

Bats and pangolin

ssRNA, 30,000 Kb

$1 \times 10^{-3} /$ base/year

10 days

$<1 \%$ (support: $\mathrm{O} 2+$ ventilation)

Droplets (airborne or contact)

Nasopharyngeal swab PCR, blood serology

> 3.5 million (99\% alive)

Acute (self-limited)

ACE-2 at pneumocytes type II

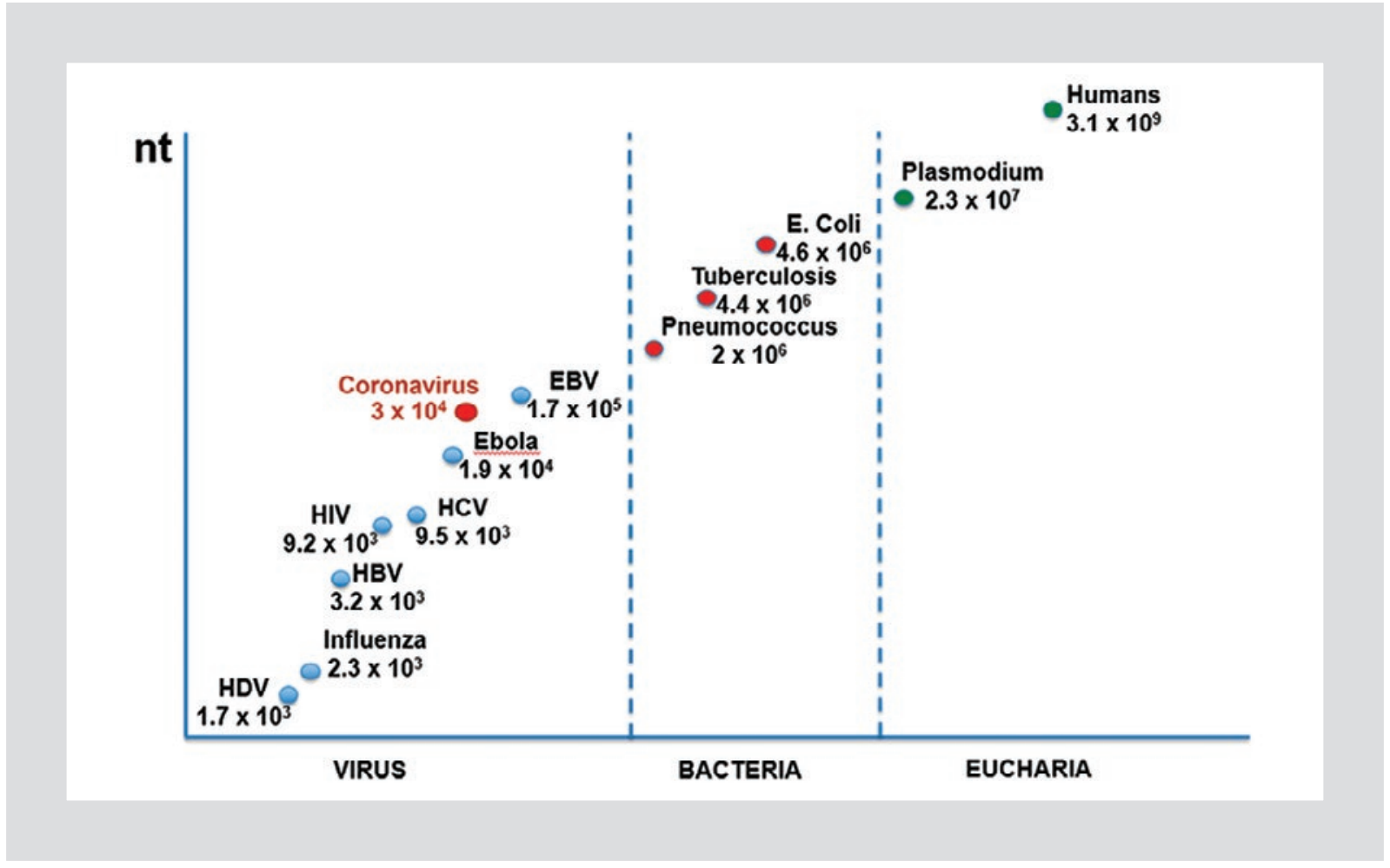

Figure 1. Genome size of living organisms. 
Table 4. Human coronaviruses

Endemic (low virulence)

CoV-229E (years 60)

CoV-OC43 (years 60)

CoV-NL63 (2003)

CoV-HKU1 (2005)

CoV: Coronavirus; MERS: Middle East Respiratory Syndrome; SARS-CoV-2: Severe Acute Respiratory Syndrome Coronavirus 2.
The SARS-CoV outbreak began in the Guangdong province in southern China in November 2002. It was linked to a zoonotic event in wild animal markets. Soon after the isolation of SARS-CoV, close coronaviruses were found in Himalayan palm civets and raccoon dogs, with $99.8 \%$ nucleotide homology to human SARS-CoV ${ }^{3}$. Further studies of wild animals demonstrated that SARS-CoV might have originated in bats when a SARS-like coronavirus was identified in Chinese horseshoe bats with a sequence similarity of $87 \%-92 \%$ with human SARS-CoV. It is believed that palm civets and raccoon dogs provided the intermediate amplification host for SARS-CoV before jumping to animal handlers in the wildlife Chinese markets ${ }^{16}$.

Transmission of SARS-CoV was primarily from person-to-person close contact, through respiratory droplets, with an incubation period of 2 to 11 days after exposure. The SARS-CoV could be shed into the environment and transferred from surfaces to the hands of patients and health-care providers. Transmission of infection could be facilitated through contact with the nose, eyes, or mouth. Hospital-acquired infections were frequent among healthcare workers. By July 2003 , the last cases of SARS were reported. A total of 8096 people in 29 countries had been infected and $774(10 \%)$ of them had died ${ }^{3}$.

To date, neither vaccines nor specific antivirals exist for SARS-CoV. Treatment of SARS entailed supportive care and use of broad-spectrum antimicrobial coverage to treat secondary bacterial infections. Advanced age (especially older than 60 years), underlying comorbidities (such as diabetes, cardiovascular disease, cancer, and chronic obstructive pulmonary disease), and high lactate dehydrogenase at presentation were independent predictors of mortality in SARS-CoV infection $^{3}$. Of note, during the SARS outbreak, there were no significant increases in morbidity or mortality in infants and children. All these SARS features remind us very much what we see with COVID-19 nowadays.

The Middle East respiratory syndrome (MERS) is a lethal zoonotic disease caused by another coronavirus, MERS-CoV, that emerged in Saudi Arabia in $2012^{17}$. Since then, sporadic cases, community clusters, and nosocomial outbreaks continue to occur in more than 30 countries. Of nearly 2500 confirmed cases, 35\% have died. The dromedary camel is the animal reservoir and source of infection to humans, although human to human transmission is well documented. The host cell DPP4 receptor is expressed on the distal airways besides other organs. The virus exhibits low transmissibility compared to SARS-CoV-2 and nearly half of cases are nosocomial. The largest hospital outbreak occurred in 2015 in South Korea with 186 cases, resulting from a single imported case. Symptomatic patients, who are nearly 50\% and generally older individuals, typically develop severe pneumonia and onethird progress to exudative diffuse alveolar damage ${ }^{17}$.

\section{SARS-CoV-2 virology and origin}

The new coronavirus is an enveloped, positive single-stranded RNA of roughly $30 \mathrm{~Kb}$. The genome codifies four structural proteins and several non-structural proteins, including the RNA-dependent RNA polymerase and the main protease (Fig. 2). The four structural proteins are the membrane (M), nucleocapsid (N), envelope (E), and spike (S). The latest confers the characteristic external "corona" appearance to the virus $^{18}$.

Protein S interacts with host receptors to mediate cell entry. The angiotensin-converting-enzyme type 2 (ACE2) acts as the viral receptor (Fig. 3) ${ }^{19}$. Interestingly, this molecule is part of the renin-angiotensin-aldosterone system that regulates blood pressure. The presence of ACE2 has been shown in multiple tissues, including the lungs, gut, and kidney. A cellular protease, known as TMPRSS2, activates the endocytosis once SARS-CoV-2 binds to ACE2.

The origin of the new coronavirus is not well known. However, the most genetically closed viral sequences have been isolated from bats, and therefore this flying mammal seems to be the animal reservoir from which it jumped to humans. An intermediate mammal (preliminarily pangolin or dogs) could have acted as intermediates driving SARS-CoV-2 rapid viral evolution and potential easier adaptation to infect humans ${ }^{20}$. For 


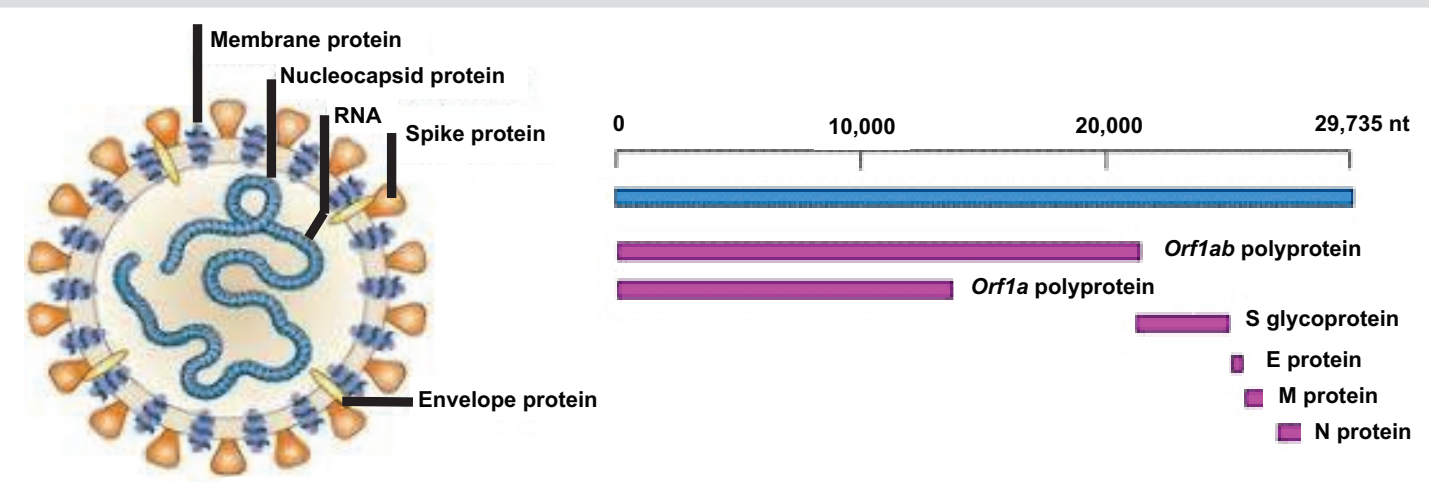

Figure 2. Coronavirus structure and genome. ${ }^{2}$

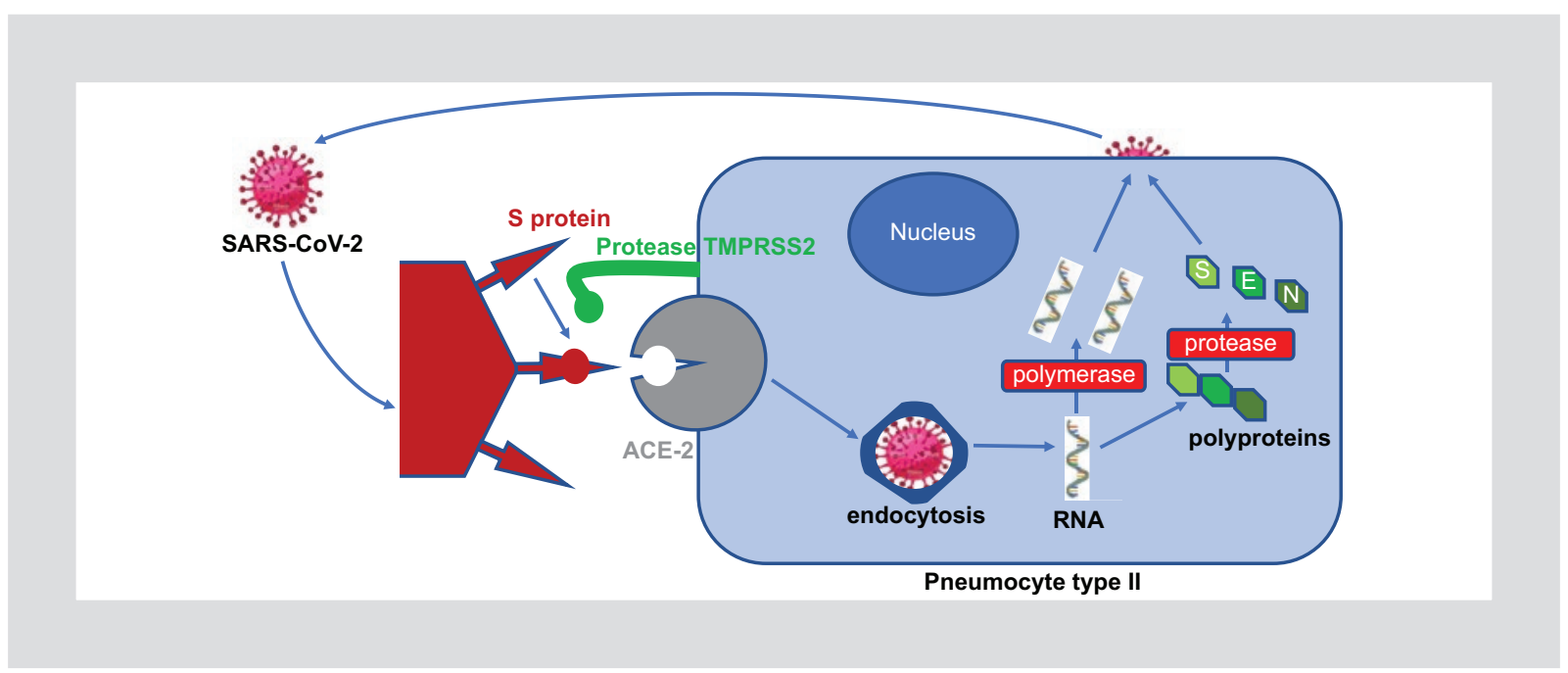

Figure 3. SARS-CoV-2 life cycle.

other pathogenic HCoVs, such as SARS-CoV and MERS-CoV, palm civets and camels were the host intermediates, respectively (Fig. 4$)^{16}$.

\section{COVID-19 transmissibility}

SARS-CoV-2 is mostly a droplet airborne transmitted virus. The efficient transmission of SARS-CoV-2 is unique compared to SARS-CoV and MERS-CoV. The virus' basic reproduction number (Ro) - that is, the average number of new cases generated by a case in an immunologically naive population, is around $3^{21}$. However, several reports have highlighted clusters in which super-spreaders were responsible for large transmission chains.
In January 18, 2020, a male that had traveled to Wuhan, go to a public bath in Huai'an, a city $700 \mathrm{~km}$ northeast of Wuhan ${ }^{22}$. He began with fever and cough the next day. During the next week, another seven men that attended the bath center (sauna, swimming pool, and showers) became infected and developed symptoms before January $30^{\text {th }}$. One employee also became sick. The age for all 9 men ranged from 24 to 50 yearsold. Thus, transmission was fast and frequent, and not significantly compromised in an environment with high temperature $\left(25-41^{\circ} \mathrm{C}\right)$ and humidity $(60 \%)^{22}$.

From January 20 to 23,2020 , a conference at the Grand Hyatt hotel in Singapore was hosted by a gas analysis company. It was attended by 109 delegates, 94 of whom came from outside of Singapore, including 


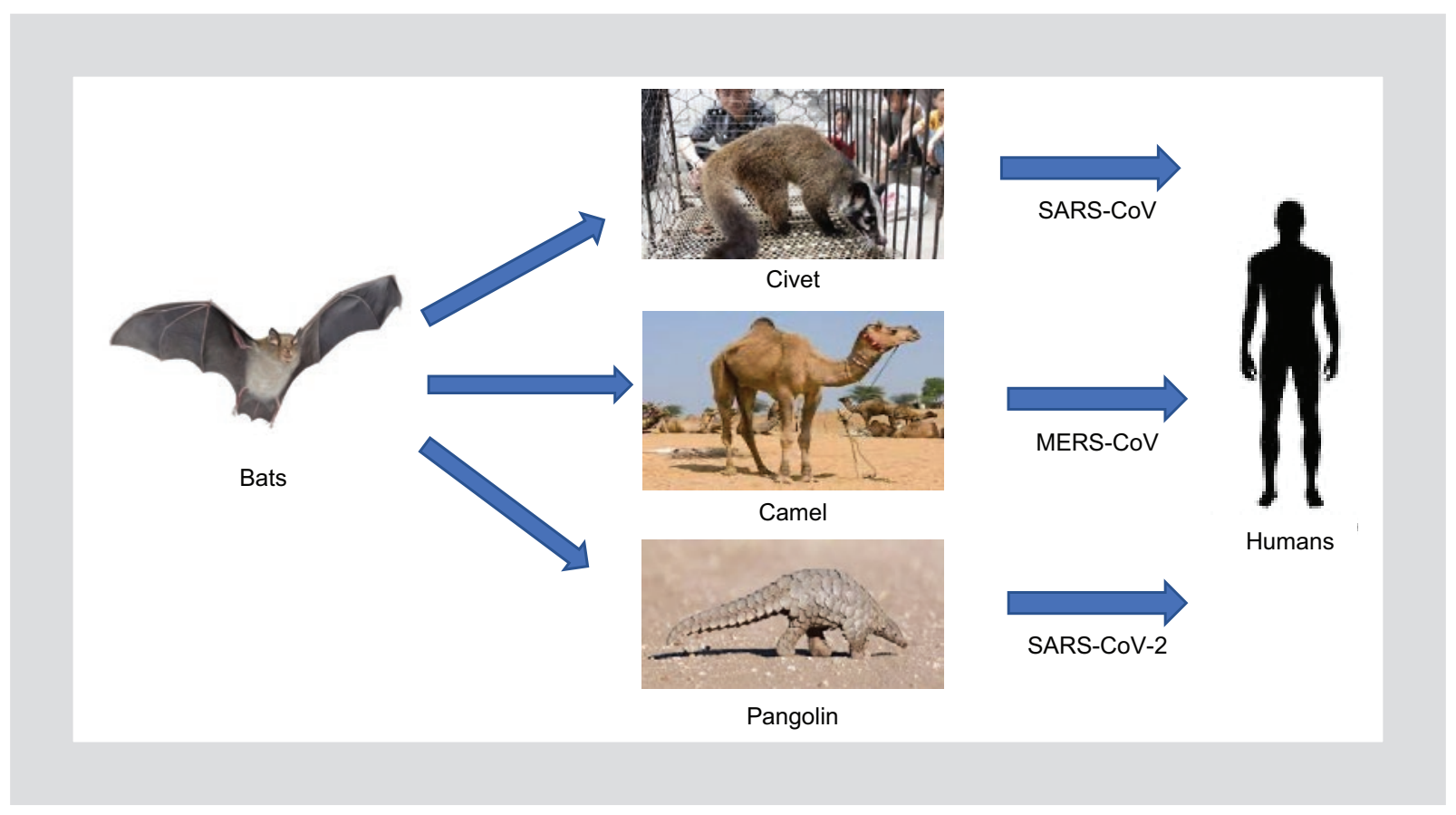

Figure 4. Origin of pathogenic human coronaviruses (zoonosis).

one attendee from Wuhan, China. As of 9 February, seven attendees had tested positive for SARS-CoV-2 in Singapore, Malaysia, South Korea, and the UK ${ }^{23}$. After leaving Singapore, a British middle-aged man traveled to a French Ski resort, where he spent 4 days in a chalet with several apartments, shared with another 21 people. He returned to the UK on January $28^{\text {th }}$ and begun experiencing symptoms on February $2^{\text {nd }}$. From 21 people infected at the ski resort, 12 were from the chalet. These persons returned to Mallorca, Spain ( $n=$ $4)$, UK $(n=6)$, or stood in France $(n=11)$. From these cases, subsequent chains of transmissions were documented at schools, clinics, and restaurants. Encouragingly, none of the 21 individuals initially involved suffered severe symptoms, and some were entirely asymptomatic infections. However, the fact that the index case was asymptomatic when he transmitted the infection to so many people raises concerns about the feasibility of containing the spread of SARS-CoV- $2^{23}$.

Transmission of SARS-CoV-2 has been demonstrated during the incubation period before patients develop symptoms ${ }^{24}$. Furthermore, transmissions may occur even from asymptomatic carriers ${ }^{24}$. A 20-yearold Chinese woman traveled from Wuhan to another city for joining a family event. During the next 3 weeks, she infected five relatives, all of whom developed symptoms. Interestingly, she remained asymptomatic all the time and had normal laboratory values and pulmonary computed tomography (CT) scan ${ }^{25}$.

In the absence of vaccines or antivirals, containment efforts are the most important procedures to slow the epidemic. Mitigation measures should include closing borders, shuttering markets, suspending internal flights, closing schools and universities, and instituting limits or outright bans on social gatherings.

\section{Clinical manifestations of COVID-19}

The proportion of people who develop symptoms after being infected with SARS-CoV-2 seems to be high but remains unclear. Several factors determine the propensity to develop severe clinical manifestations, being older age the most important (Fig. 5).

The cruise ship Diamond Princess was a natural experiment for COVID-19. Of 3800 sailors and tourists mostly older people - 712 became infected and seven died, whereas up to $18 \%$ of those infected remained asymptomatic ${ }^{26}$. More recently, the US aircraft carrier Theodore Roosevelt was another natural experiment. Almost the entire crew of 4800 sailors was tested-mostly young healthy people. From 600 positives, only $40 \%$ had experienced symptoms and only one died. Outside these observations, the experience reported so far with children and adolescents is even greater for the proportion of asymptomatic infections. Even so, however, a subset of infants may develop severe pneumonia ${ }^{27}$. 


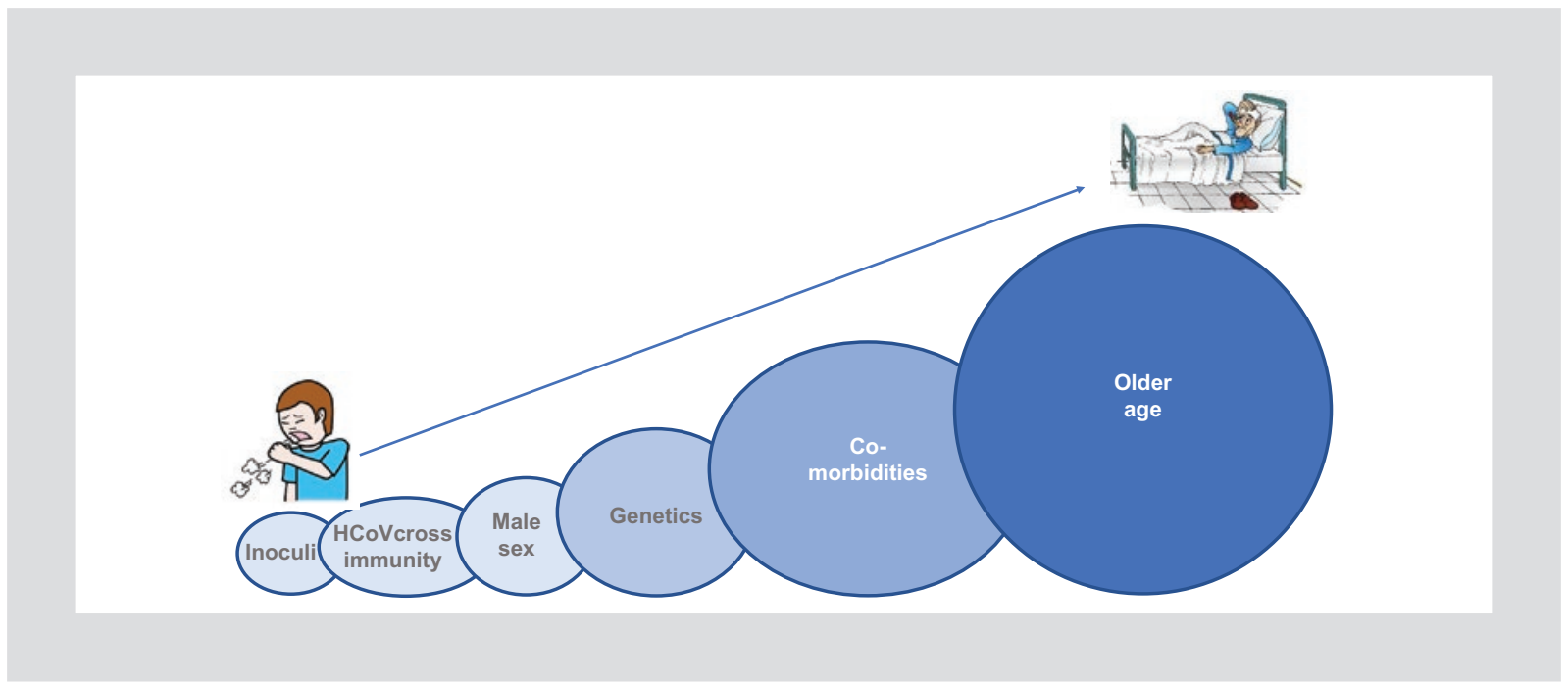

Figure 5. Major determinants of COVID-19 disease severity.

Although estimates of asymptomatic SARS-CoV-2 infections are high, the rapid propagation of the new droplet airborne virus may result in very high numbers of mild and severe cases within a few weeks in an allnaïve (susceptible) community. In this scenario, most health-care facilities may become overwhelmed and collapse, as recently experienced in Madrid ${ }^{28}$ or New York city ${ }^{29}$. Many deaths during the earlier weeks of the epidemic occur in the most vulnerable groups, such as older patients and those with co-morbidities (diabetes, pulmonary chronic disease, renal insufficiency, cardiovascular disease, obesity, etc. ${ }^{30}$. In Spain, $80 \%$ of the first 20,000 deaths occurred until mid-April 2020 were seen in persons over 70 years old. Interestingly, HIV infection by itself did not emerge as a negative predictor of COVID-19 severity or mortality, most likely because most HIV+ individuals are aviremic and depict normal CD4 counts under antiretroviral therapy ${ }^{12,13}$.

On exposure to the virus, generally following inhalation of virus-containing airborne droplets, or throughout contact with contaminated surfaces, viral replication begins and first symptoms appear within a few days. The mean incubation period is of 5 days, although it ranges from 2 to 15 days. The inoculum size seems to play a role, with shorter legs and more intense symptoms/signs with large inoculum. Anyway, asymptomatic cases seem to be frequent, especially in children and young adults. This subset of patients, however, can transmit the virus ${ }^{25}$. For people complaining fever and cough, other typical complaints are dyspnea, fa- tigue, hyposmia, dysgeusia, cephalea, and less frequently gastrointestinal symptoms ${ }^{30-32}$.

In older patients and in those with co-morbidities, pulmonary deterioration may occur, often suddenly around 1 week after the first symptoms appear ${ }^{33,34}$. Bilateral lung patches are seen on CT scans. Hypoxemia and respiratory distress reflect a pulmonary cytokine storm rather than bacterial superinfection ${ }^{35}$. A subset of these patients requires mechanical ventilation and intensive care unit support. Unfortunately, prognosis is poor for this group, with fatality rates of nearly $50 \%$ (Fig. 6).

Given that clinicians and nurses are critical in the management of the large waves of sick patients coming during the $1^{\text {st }}$ week on COVID-19 enters a community keeping uninfected care providers is crucial|28,29,36. This bottleneck for proper contention is not the only one. A shortage of medical resources (beds, ventilators, etc.) has been equally relevant (Fig. 7). Unfortunately, the last shortage has been for personal protective equipment (masks, gloves, coats, etc.) in many places, accounting for large numbers of physicians and nurses becoming sick or left out on quarantine during the critical days when they were more needed.

\section{COVID-19 pathogenesis}

The disease that characterizes SARS-CoV-2 infection follows the pattern of other viral respiratory illnesses, with typical flu-like symptoms during the $1^{\text {st }}$ week. Symptomatic patients experience fever and cough, 


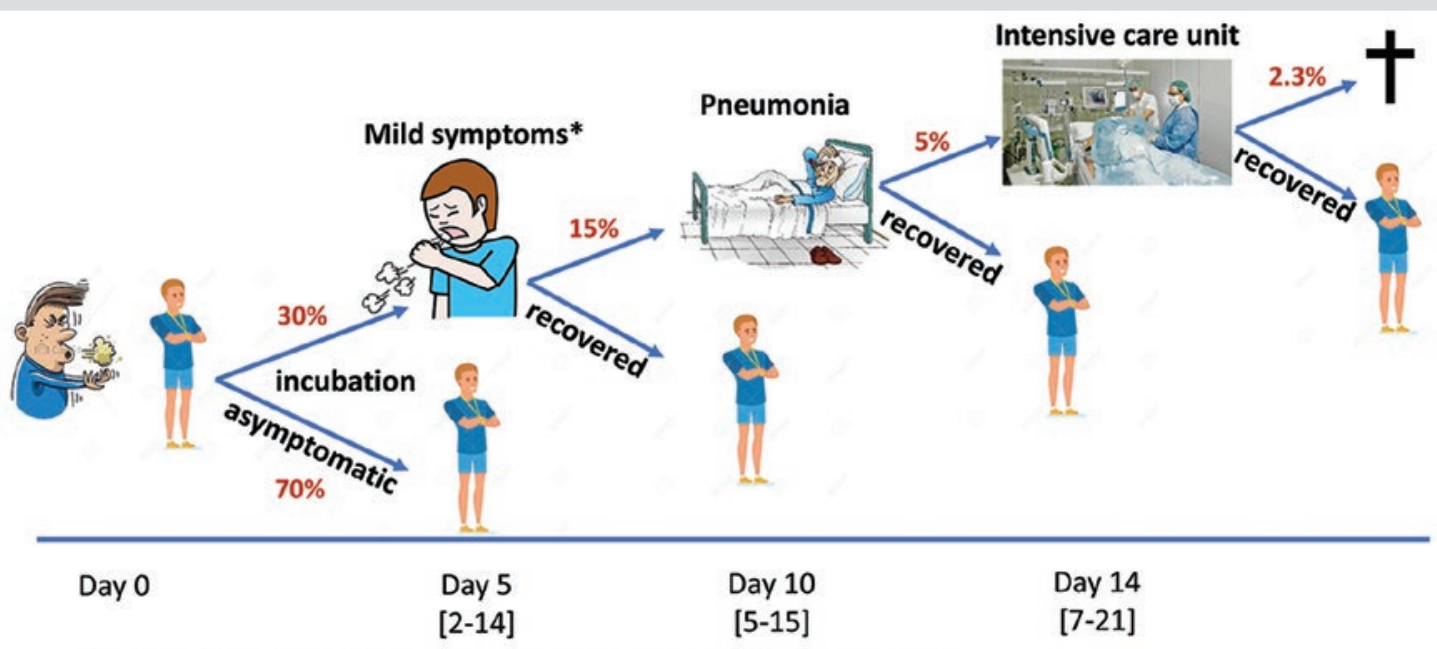

*Fever, cough, cephalea, fatigue, anosmia, disgueusia, myalgia, etc.

Figure 6. Clinical course of SARS-CoV-2 infection ${ }^{28}$.

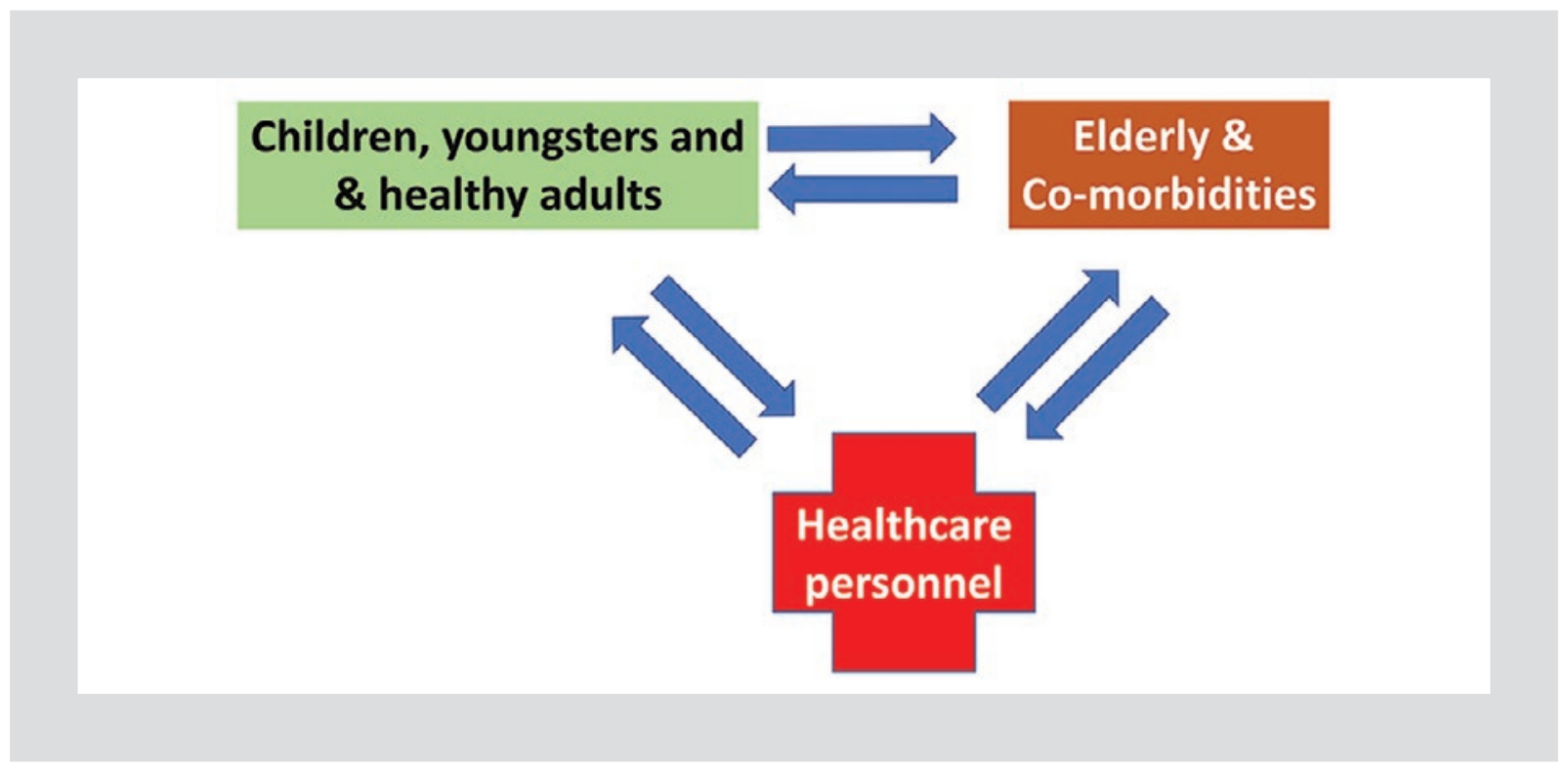

Figure 7. COVID-19 population stratification for public health interventions ${ }^{28}$.

and less frequently malaise, fatigue, headache, myalgia, diarrhea, etc. The development of adaptive immune responses controls viral replication and ends illness. However, in a subset of patients, infection of macrophages and dendritic cells may subsequently trigger a cytokine release syndrome. A dysregulated production of interleukin 6 at the lungs may lead to inflammatory phenomena and increased vascular per- meability that ultimately may result in acute respiratory distress syndrome ${ }^{37}$.

Harvard researchers recently proposed a 3-phase staging clinical-therapeutic system for COVID-1938. During the first phase (mild), viral replication following infection of the upper respiratory tract leads to cough and fever. In the second phase (pulmonary), viral infection of the low respiratory tract is accompanied by lung infiltrates 


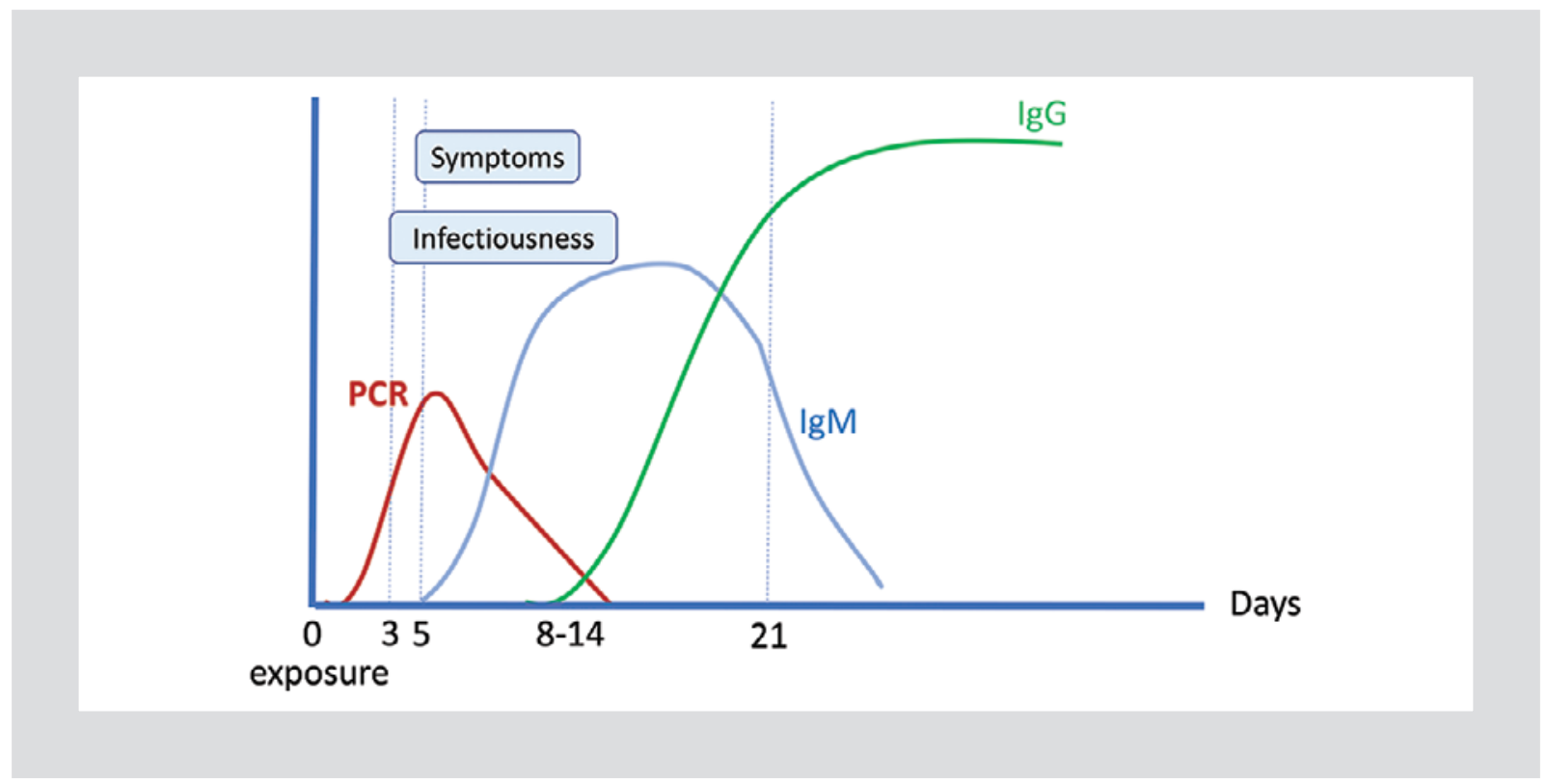

Figure 8. SARS-CoV-2 antibody response dynamics.

and hypoxemia. In the third phase (inflammatory), the immune response elicited against the virus on the lungs may exacerbate pulmonary dysfunction, with acute respiratory distress ${ }^{33,35}$. The pathological findings in the lungs of patients with COVID-19 resemble those of patients who died from SARS and MERS, with profound tissue damage associated with hyperinflammatory responses 39,40 .

\section{SARS-CoV-2 diagnostics}

Within a couple of days following exposure and initial SARS-CoV-2 replication in the respiratory tract, the first symptoms begin, generally as fever and/or cough. During the incubation period, viral nucleic acids can be detected using polymerase chain reaction (PCR) on nasopharyngeal swabs, and even on saliva. Positive PCR last for 1-2 weeks even after symptoms have vanished. The period of positive PCR must be interpreted as the contagious timeframe. Specific immunoglobulin $\mathrm{M}(\mathrm{Ig} \mathrm{M})$ antibodies appear soon but last for only 1-3 weeks. In contrast, specific IgG appears later, after 2-4 weeks of exposure, and steadily increase and stay

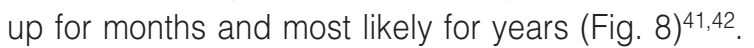

Several PCR tests have been developed for the diagnosis of acute SARS-CoV-2 infection. False negatives may occur in individuals with low viral load, who generally exhibit minimal or no symptoms at all. More than one viral genome region should be targeted. Detection of SARS-CoV-2 antigens has been examined as a more feasible tool replacing PCR, but low sensitivity is an important concern. The recognition of specific IgM and mostly IgG has been developed for characterizing individuals that have developed immunity, as result of past exposure. Rapid tests using capillary blood on finger prick or even saliva are increasingly been used for testing people once the epidemic has peaked, to prioritize who may resume back to work without risks ${ }^{28}$.

\section{Therapeutic approaches for COVID-19}

Given that SARS-CoV-2 infection is generally a selflimited illness, treatment goals should aim to reduce the severity of clinical symptoms and prevent complications. In addition, research on vaccines and/or chemoprophylaxis should aim to the desirable goal of preventing viral infection and limit global disease burden. As with influenza, the benefit of any direct antiviral against the coronavirus, will exhibit its best profile reducing the length and intensity of clinical symptoms. This is the case for oseltamivir or zanamivir when given during the first 2 days of clinical manifestations of flu. Thus, prompt use is critical for maximizing any COVID-19 antiviral efficacy.

Regulatory agencies such as the US Food and Drug Administration and the European Medical Agency are taking unprecedented open views for accelerating the evaluation and approval of potential therapeutic agents 
for COVID-19, never considered before for other medicines, including antiretrovirals for HIV43. This new approach is being applied for both new drug development and for drug re-purposing, meaning wider prescription of drugs that already are approved for treating other illnesses.

Chinese researchers assessed the efficacy of ritonavir-boosted lopinavir in an open-label randomized trial in 199 COVID-19 hospitalized adult patients. Overall, no clinical nor virological benefits were recognized compared to the standard of care, with a mortality rate of $19 \% 44$.

In an international cohort of 53 hospitalized patients with severe COVID-19 (64\% were on ventilation), intravenous remdesivir for 10 days provided good safety and efficacy, with improvement in oxygen demands ${ }^{45}$. The overall mortality was $13 \%$. Unfortunately, viral load response was not monitored.

More recently, Chinese researchers described the crystallography of the SARS-CoV-2 main protease $\left(\mathrm{M}^{\mathrm{pro}}\right)$, a homodimer enzyme critical for viral replication that cuts the original polyprotein ${ }^{46}$. Since $M^{\text {pro }}$ has no closely related homologues in humans, several compounds already approved for treating other illnesses were found to inhibit $M^{\text {pro }}$ throughout virtual drug screening, including disulfiram, ebselen, and tideglusib. Disulfiram is approved for the treatment of chronic alcoholism. Ebselen is a Japanese compound developed for psychiatric bipolar conditions. Tideglusib is a drug being developed for treating Alzheimer's disease. Ongoing trials will test their efficacy in COVID-19 patients.

The real clinical value of other antiretrovirals or antivirals against SARS-CoV-2 remains unclear and randomized trials should be needed to prove whether drug re-purposing is enough or new molecules must be developed ${ }^{47,48}$.

Given the unique immunopathogenic mechanism of respiratory distress that characterizes the severe forms of COVID-1933-35,37, at this time remains unclear, which would the benefit of antivirals once the cytokine storm has been triggered. At that stage, it seems reasonable to believe that anti-inflammatory agents, ranging from corticosteroids or hydroxychloroquine ${ }^{49}$ to monoclonal cytokine blockers, might be more efficacious. Immunomodulators, such as tocilizumab, and anti-IL6 antibody, anti-tumor necrosis factor antibodies such as infliximab or adalimumab are currently being tested $37,50,51$. The use of powerful antiinflammatory drugs in acute viral diseases has to be approached with caution because of the risk of in- creasing viral replication or bacterial infections. Another caveat is whether patients with rheumatic or autoimmune illnesses treated with immunomodulatory agents might be protected from developing severe forms of COVID-19.

After respiratory viral infection, superinfections with other organisms occur at the most severe end of the disease spectrum ${ }^{52}$. Experimental studies suggest that if the duration of inflammation is prolonged, with its associated collateral lung damage, bacterial superinfections are the rule. This observation explains why bacteria might have a role in COVID-19. Indeed, azithromycin has been given quite often in hospitalized COVID-19 patients.

Despite being a RNA virus, the genetic variability of SARS-CoV-2 is limited by the activity of a viral endonuclease that repairs replication genome errors. This circumstance may favor the development of a protective vaccine. The spike (S) and the nucleocapsid (N) are tested as appropriate immunogenic targets ${ }^{53}$. However, even in the best scenario, widely access to a vaccine for COVID-19 would not be feasible before Christmas.

\section{A second wave of COVID-19}

COVID-19 has emerged as an unprecedented public health threat. We were not prepared for such a pandemic crisis. During the $1^{\text {st }}$ weeks of the introduction of the virus in a community, there has been uniformly a shortage of physicians and nurses, since many have become sick or put under quarantine leaving. The shortage of health staff resources occurred along with increasing large waves of incoming ill patients ${ }^{28,29}$. In parallel, there was a lack of enough hospital beds and ventilators for such a large volume of incoming patients. The result of such concomitant failures was tragic: many severely ill patients, mostly elderly, did not receive adequate health support and died, often in emergency unit corridors or alone in geriatric residences ${ }^{28,29}$.

After 2 months of suffering the pandemic, the situation has changed in most places hit earlier on. Both human and physical resources have improved, with the allocation of more doctors and nurses (many already recovered from COVID-19) and provision of larger numbers of hospital beds and ventilators (Fig. 9) (4,55. $^{5}$.

A second wave of COVID-19 cases and deaths will most likely occur accompanying relaxation of confinement, social distancing measures, and return to work. Importantly, this is the time when governments should 

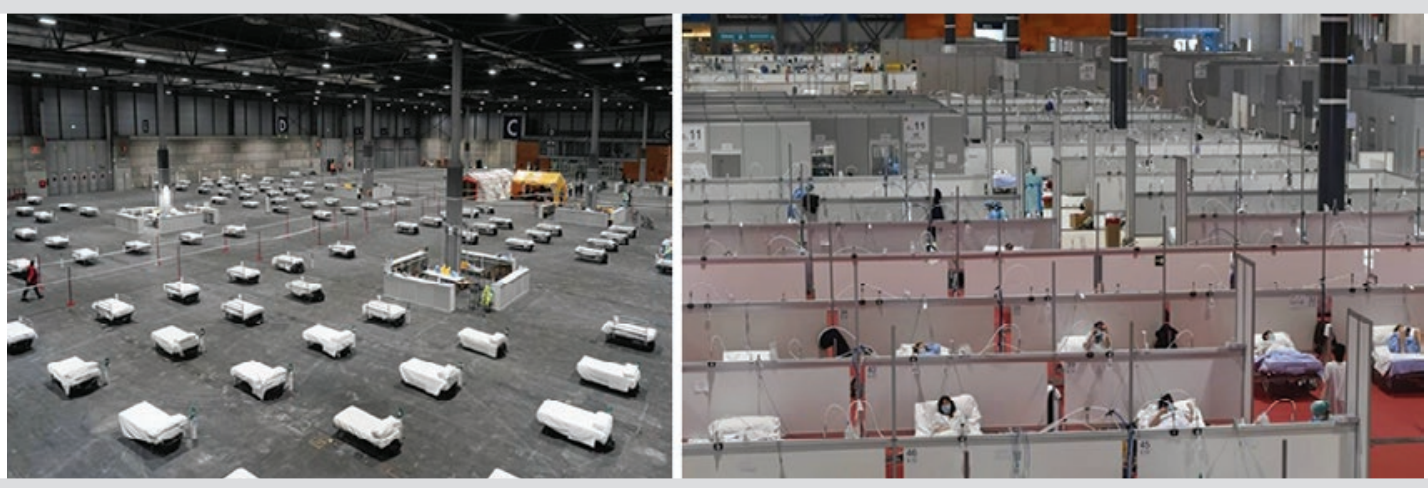

Figure 9. Medicalized exhibition halls for COVID-19 built within 1 week in Madrid, Spain (March 2020)28.

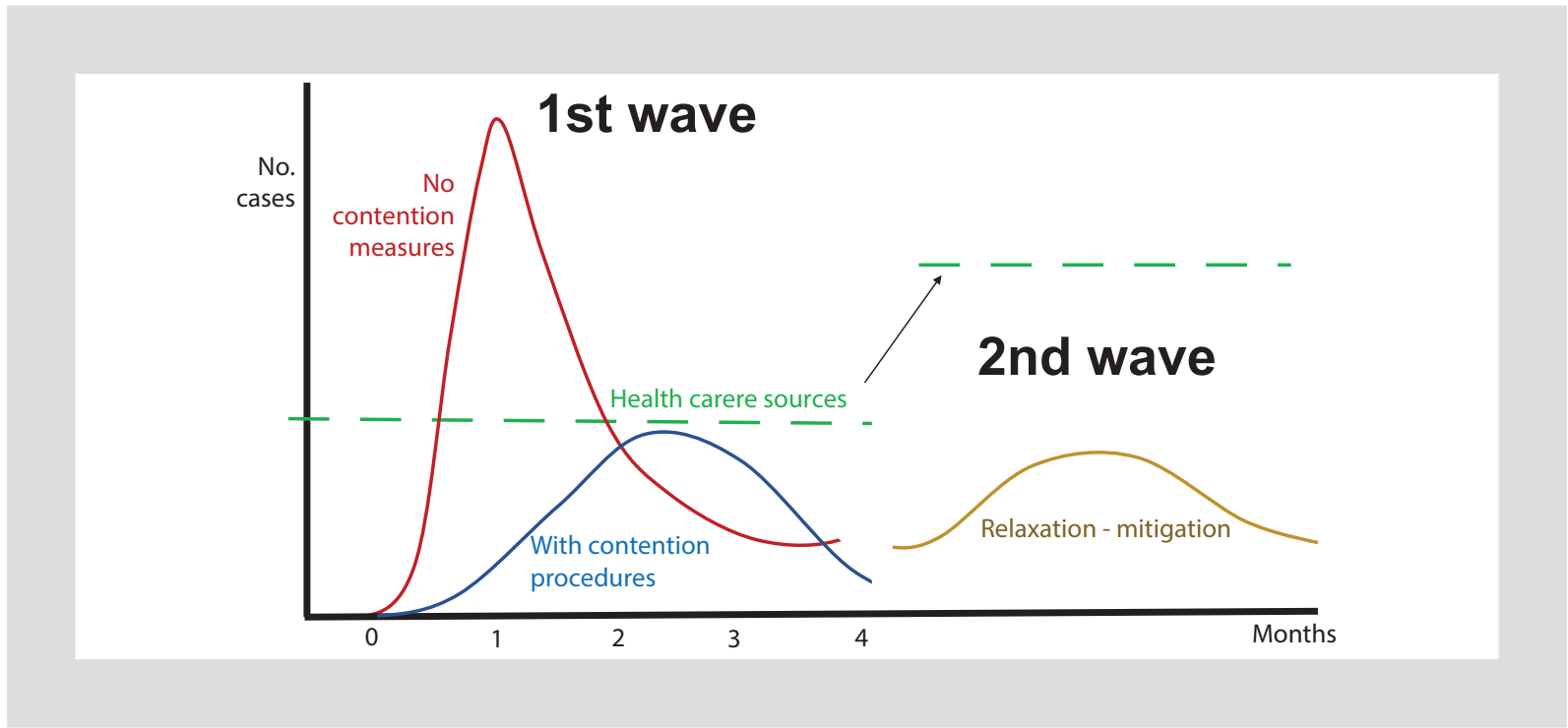

Figure 10. Dynamics of COVID-19 in a community. Impact of social disconnecting and health-care resources capacity preparedness ${ }^{28}$.

act and prepare immediately to ensure that the healthcare system has adequate labor, resources, and facilities to minimize the mortality risk of unanticipated COVID-1928,29. If doing so, as shown in figure 10 , the expected burden of cases and especially on fatalities will be much lower. During the first wave, the tremendous impact occurred during a short timeframe, with the greatest case incidence and deaths occurring in communities that had not taken preventive measures on advance $28,29,54,55$. On the contrary, in places where actions had been taken before, the medical and even economic impact has been ameliorated. As example, at UNIR, the institution of one of us, most employees were sent home almost immediately on early March, before the COVID-19 outbreak exploded in Madrid, Spain. Using a stratification of job categories from less to more expendable, telejob was implemented. Since then, homework has been the rule and no fatalities have occurred so far ${ }^{56}$.

As the COVID-19 epidemic progress within a given community, the number of recovered patients becomes larger and confers a kind of social protection against further transmissions, a phenomenon known as "herd immunity," meaning that there is a point when susceptible people are no longer enough to sustain the Ro transmissibility needed to support the epidemic (Fig. 11). In Spain, at the end of March 2020, estimates of $15 \%$ of the whole population already exposed to SARS-CoV-2 had been reported ${ }^{57}$. In some groups, 


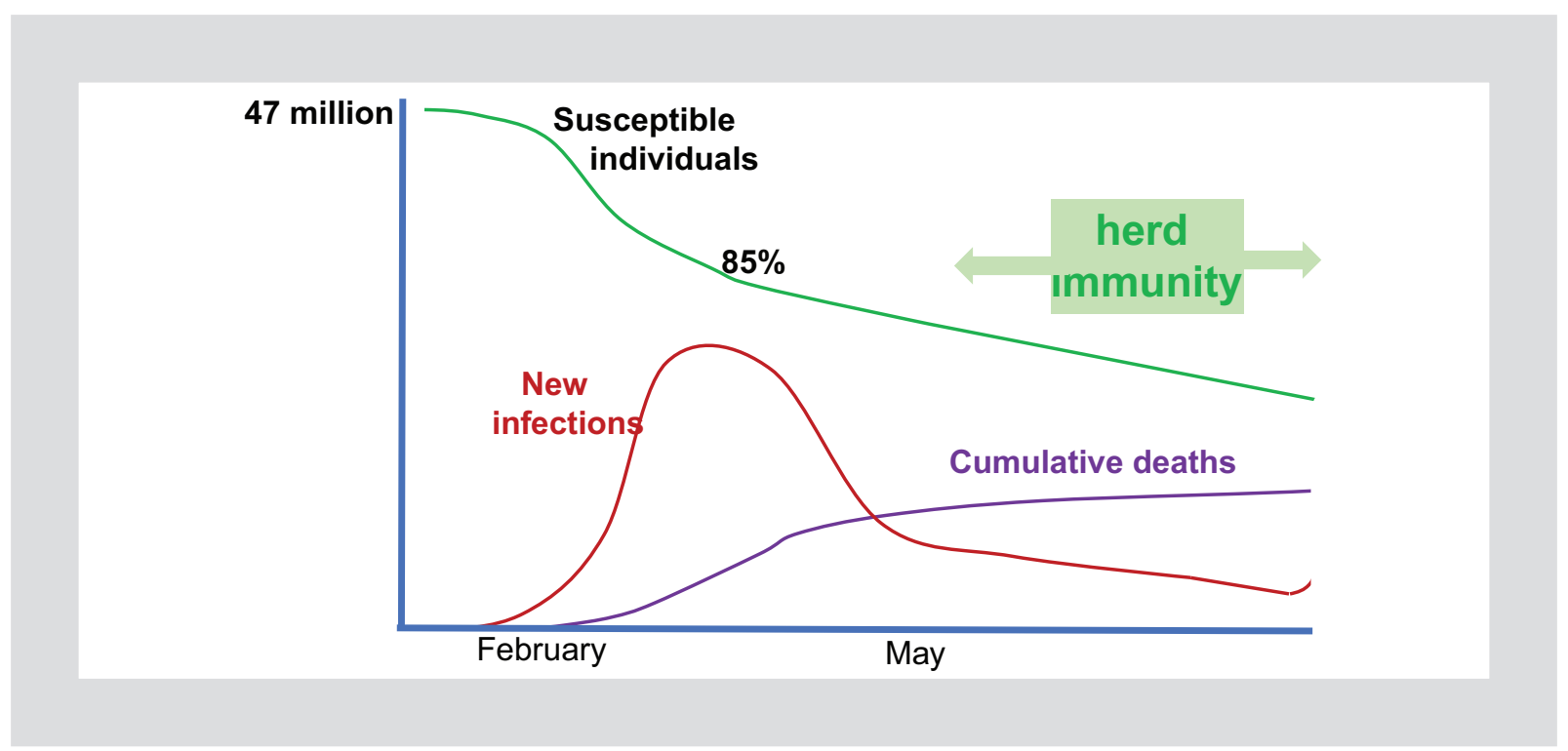

Figure 11. Projection of SARS-CoV-2 infection in Spain ${ }^{28}$.

including healthcare workers, this proportion is for sure much greater. Massive SARS-CoV-2 antibody testing must be implemented as soon as possible, beginning for socially critical population groups, such as healthcare workers ${ }^{58}$. This will ensure that already immune people (seropositives) may return safely back to their tasks, without risk for them or others. For seronegatives, cautions must be reinforced when going back to work and periodic repeated testing should be encouraged.

\section{Prospects after COVID-19}

It would be a before and after COVID-19. Besides transforming health-care services, other dimensions of our lives will no longer be the same. At social level, the selective impact on the most vulnerable populations, including the elderly and handicapped populations, will have consequences in rich countries. No doubt that discussion on retirement pensions or even euthanasia will be forgotten for a while. Public budget commitments for these groups, considered as non-productive sectors of the population, will relax. This funding would be liberated for other needs. COVID-19 is rapidly moving from being a health crisis to become a deep economic crisis. Indeed, the International Monetary Fund has alerted that COVID-19 is driving to the most important financial crack after one century, somewhat resembling the Great Depression (1929).
At global level, disruption of low and middle classes will be massive in many countries. As a consequence, one can speculate that concentration of power in oligarchies will occur. Efforts for keeping alive enterprises are being made by some rich countries, including strategies for calling back to work employees, including stepwise returns using widely antibody testing (Fig. 12) ${ }^{28}$.

Given that a significant proportion of the population in most communities will remain uninfected after peaking the first COVID-19 wave, a second wave should be expected once relaxation of confinement progress ${ }^{59}$. This time, the protection of health-care providers, namely, physicians and nurses, must be ensured from the beginning ${ }^{36}$. Furthermore, medical attention to other medical conditions should not be compromised as, sadly, it has happened during the first COVID-19 wave for patients with cancer, cirrhosis, trauma, surgery, etc., even sexually transmitted diseases ${ }^{60,61}$. The principle of equity must prevail, especially when there is as a shortage of resources ${ }^{62}$.

Finally, as the COVID-19 pandemic sweeps the globe, causing tens of thousands of deaths and massive economic disruption, numbers from Africa are like the early drops of rain before the clouds open up. A storm is building there, and the 1.2 billion people living in Africa are at tremendous risk. Uniquely, whereas the population is younger, access to medical care is rather scarce. Finally, it is critically important that resources and atten- 


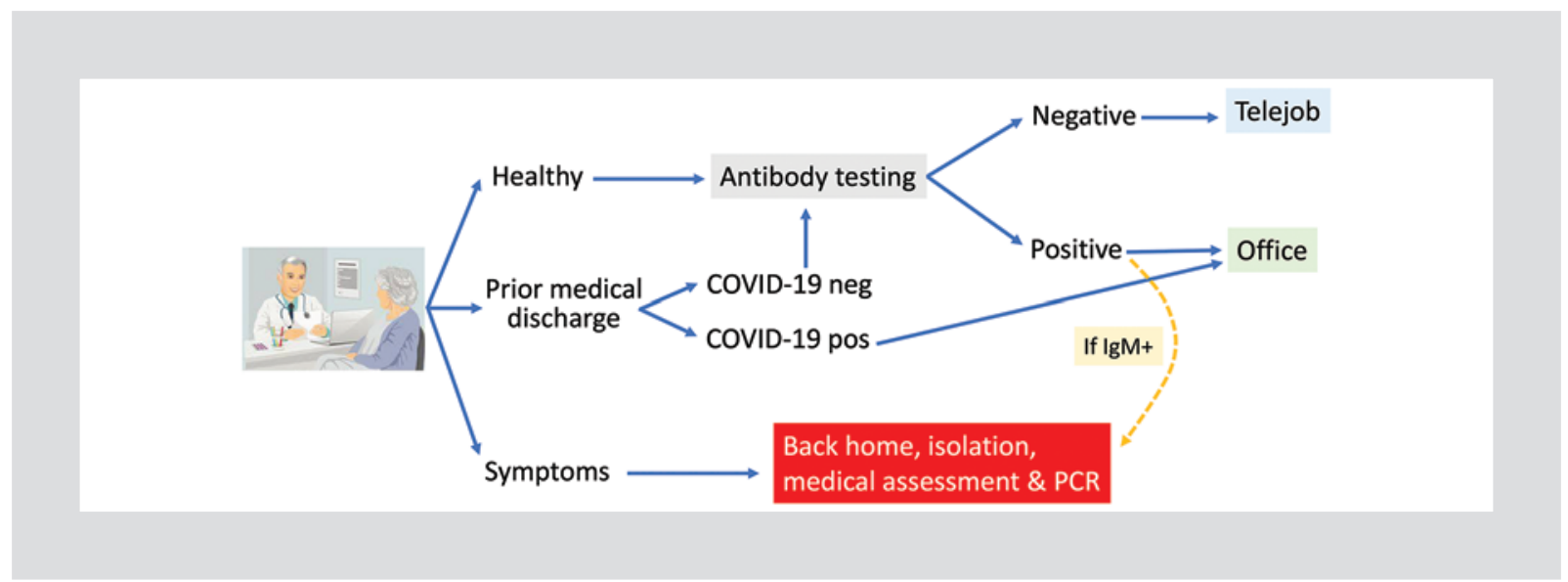

Figure 12. Back to work strategy.

tion in Africa are not be diverted from the continent's ongoing threats from other infectious diseases, such as HIV, tuberculosis, and malaria ${ }^{63}$.

Research on COVID-19 vaccines is rapidly being developed, but ultimately a protective vaccine will not be available until the next year, once the hit of the first wave and even the second already have ended ${ }^{53}$. Hopefully, it would be available for confronting new waves as COVID-19 shifts to be another seasonal cold, with SARSCoV-2 co-circulating with other respiratory viruses, including its closest relatives, the four endemic HCoVs.

As medical doctors, a last thought emerging from the extreme COVID-19 experiences is the refreshment of our vulnerability, as individuals and as society. There is no room for self-sufficiency and unlimited confidence in our science. Everyone has been on hold, everyone can dye. Along this thought, another regards the essence of our profession, as pointed out by great figures such as Osler, Lejeune, or Pellegrino ${ }^{64-66}$. This is a great opportunity to be proud and to revive the major values of our Hippocratic oath: cure, alleviate, and accompany our patients.

\section{References}

1. Chen N, Zhou M, Dong X, Qu PJ, Gong F. Epidemiological and clinical characteristics of 99 cases of 2019 novel coronavirus pneumonia in Wuhan, China: a descriptive study. Lancet. 2020;395:507-13.

2. Coronaviridae Study Group of the International Committee on Taxonomy of Viruses. The species severe acute respiratory syndrome-related coronavirus: classifying 2019-nCoV and naming it SARS-CoV-2. Nat Microbiol. 2020:5:536-44.

3. Peiris J, Guan Y, Yuen K. Severe acute respiratory syndrome. Nat Med. 2004; 10:88-97.

4. Monto A, Fukuda K. Lessons from Influenza pandemics of the last 100 Years. Clin Infect Dis. 2020;70:951-7.

5. Soriano V, Ramos JM, Barreiro P, Fernández-Montero JV. AIDS clinical research in Spain large HIV population, geniality of doctors, and missing opportunities. Viruses. 2018:10:E293.

6. Benítez-Gutiérrez L, Soriano V, Requena S, Arias A, Barreiro P, de Mendoza C. Treatment and prevention of HIV infection with long-acting antiretrovirals. Expert Rev Clin Pharmacol. 2018;11:507-17.

7. de Mendoza C, Lozano AB, Caballero E, Cabezas T, Ramos JM, Soriano $\mathrm{V}$. Antiretroviral therapy for HIV-2 infection in non-endemic regions. AIDS Rev. 2020;22:44-56.

8. Ramos JM, de Mendoza C, Aguilera A, Barreiro P, Benito R, Eiros JM, et al. Spanish HTLV Network. Hospital admissions in individuals with HTLV-1 infection in Spain. AIDS. 2020; [Epub ahead of print]

9. Soriano V, Tefferi A. Prevention of liver cancer with new curative hepatitis C antivirals: real-world challenges. Cancer. 2018;124:1647-9.

10. Soriano V, Aguilera A. Hepatitis delta enters a new therapeutic era. $\mathrm{J}$ Infect Dis. 2018;217:1173-6.

11. Hargreaves J, Davey C. Three lessons for the COVID-19 response from pandemic HIV. Lancet HIV. 2020:20:30110-7.

12. Soriano V, Barreiro P. Impact of new coronavirus epidemics on HIV-infected patients. AIDS Rev. 2020;22:57-8.

13. Blanco JL, Ambrosioni J Garcia F, Martínez E, Soriano A, Mallolas J. COVID-19 in patients with HIV: clinical case series. Lancet HIV. 2020; [Epub ahead of print].

14. Domingo $E$, Schuster $P$. What is a quasispecies? Historical origins and current scope. Curr Top Microbiol Immunol. 2016:392:1-22.

15. Gaunt E, Hardie A, Claas E, Simmonds P, Templeton K. Epidemiology and clinical presentations of the four human coronavirus 229E, HKU1, NL63 and OC43 detected over 3 years using a novel multiplex real-time PCR method. J Clin Microbiol. 2010:48:2940-7.

16. Zhou $P$, Yang $X$, Wang $X, H u$ B, Zhang W, Si HR, et al. A pneumonia outbreak associated with a new coronavirus of probable bat origin. Nature. 2020:579:270-3

17. Memish Z, Perlman S, Van Kerkhove M, Zumla A. Middle East respiratory syndrome. Lancet. 2020;395:1063-77.

18. Wu A, Peng Y, Huang B, Ding X, Wang X, Niu P, et al. Genome composition and divergence of the novel coronavirus (2019-nCoV) originating in China. Cell Host Microbe. 2020;27:325-8.

19. Letko M. Marzi A. Munster V. Functional assessment of cell entry and receptor usage for SARS-CoV-2 and other lineage B betacoronaviruses. Nat Microbiol. 2020;5:562-9.

20. Xia X. Extreme genomic CpG deficiency in SARS-CoV-2 and evasion of host antiviral defense. Mol Biol Evol. 2020; [Epub ahead of print].

21. Li Q, Guan X, Wu P, Wang X, Zhou L, Ren R, et al. Early transmission dynamics in Wuhan, China, of novel coronavirus-infected pneumonia. N Engl J Med. 2020:382:1199-207.

22. Luo C, Yao L, Zhang L, Yao M, Chen X, Wang Q, et al. Possible transmission of SARS-CoV-2 in a public bath center in Huai'an, Jiangsu Province, China. JAMA Network Open. 2020;3:e204583.

23. Hodcroft E. Preliminary case report on the SARS-CoV-2 cluster in the UK, France and Spain. Swiss Med Wkly. 2020;150:w20212.

24. Huang L, Zhang X, Zhang X, Wei Z, Zhang L, Xu J, et al. Rapid asymptomatic transmission of COVID-19 during the incubation period demonstrating strong infectivity in a cluster of youngsters aged 16-23 years outside Wuhan and characteristics of young patients with COVID-19: A prospective contact-tracing study. J Infect. 2020;1:1-8.

25. Bai $Y$, Yao L, Wei T, Tian F, Jin DY, Chen L, et al. Presumed asymptomatic carrier transmission of COVID-19. JAMA. 2020;323:1406-7.

26. Rajgor D, Lee M, Archuleta S, Bagdasarian N, Quek S. The many estimates of the COVID-19 case fatality rate. Lancet Infect Dis. 2020;20:30244-9.

27. Dong $Y, M o X, H u Y$, Qi X, Jiang F, Jiang Z, et al. Epidemiology of COVID-19 among children in China. Pediatrics. 2020;16:e20200702. 
28. Soriano V, Barreiro P. Why such excess of mortality for COVID-19 in Spain? Ther Adv Infect Dis. [Epub ahead of print]

29. Goyal P, Choi J, Pinheiro L, Schenck EJ, Chen R, Jabri A, et al. Clinical characteristics of COVID-19 in New York City. N Engl J Med. 2020; [Epub ahead of print].

30. Huang C, Wang Y, Li X, Ren L, Zhao J, Hu Y, et al. Clinical features of patients infected with 2019 novel coronavirus in Wuhan, China. Lancet. 2020;395:497-506

31. Tian Y, Rong L, Nian W, He Y. Gastrointestinal features in COVID-19 and the possibility of faecal transmission. Aliment Pharmacol Ther. 2020; 51:843-51.

32. Ollarves MF, Rodriguez A, Bonilla D, Rodriguez A. Anosmia in a healthcare worker with COVID-19 in Madrid, Spain. Travel Med Infect Dis. 2020:1:101666.

33. Pedersen S, Ho YC. SARS-CoV-2: a storm is raging. J Clin Invest. 2020;1:137647

34. Wang L, He W, Yu X, Hu D, Bao M, Zhao J, et al. Coronavirus disease 2019 in elderly patients: characteristics and prognostic factors based on 4-week follow-up. J Infect. 2020;S0163-4453:30146-8.

35. Conti P, Ronconi G, Caraffa A, Ross R, Frydas I, Kritas S. Induction of pro-inflammatory cytokines (IL-1 and IL-6) and lung inflammation by coronavirus-19 (COVI-19 or SARS-CoV-2): anti-inflammatory strategies. J Biol Regul Homeost Agents. 2020;34:1

36. Chirico F, Nucera G, Magnavita N. COVID-19: protecting healthcare workers is a priority. Infect Control Hosp Epidemiol. 2020;17:1-4.

37. Moore J, June C. Cytokine release syndrome in severe COVID-19. Science. 2020;17:eabb8925.

38. Siddigi H, Mehra M. A clinical-therapeutic staging proposal. J Heart Lung Transplant. 2020;1-18.

39. Xu Z, Shi L, Wang Y, Zhang J, Huang L, Zhang C, et al. Pathologica findings of COVID-19 associated with acute respiratory distress syndrome. Lancet Respir Med. 2020;8:420-2.

40. Liu J, Zheng X, Tong Q, Li W, Wang B, Sutter K, et al. Overlapping and discrete aspects of the pathology and pathogenesis of the emerging human pathogenic coronaviruses SARS-CoV, MERS-CoV, and 2019nCoV. J Med Virol. 2020;92:491-4

41. Loeffelholz M, Tang TW. Laboratory diagnosis of emerging human coronavirus infections the state of the art. Emerg Microb Infect. 2020:9:747-56.

42. Guo L, Ren L, Yang S, Yang F, Wang Y, Wu C, et al. Profiling early humoral response to diagnose novel coronavirus disease (COVID-19). Clin Infect Dis. 2020;21:ciaa310.

43. de Mendoza C, Soriano V. Tough requirements for new antiretroviral drugs. Lancet HIV. 2020;7: e150-e151.

44. Cao B, Wang Y, Wen D, Liu W, Wang J, Fan G, et al. A trial of lopinavir ritonavir in adults hospitalized with severe Covid-19. N Engl J Med. 2020;18:NEJMoa2001282

45. Grein J, Ohmagari N, Shin D, Diaz G, Asperges E, Castagna A, et al. Compassionate use of remdesivir for patients with severe COVID-19. N Engl J Med. 2020:10:NEJMoa2007016.

46. Jin Z, Du X, Deng Y, Xu Y, Deng Y, Liu M, et al. Structure of $M^{\text {pro from }}$ COVID-19 virus and discovery of its inhibitors. Nature. 2020;9:2223.
47. Ford N, Vitoria M, Rangaraj A, Norris S, Calmy A, Doherty M. Systematic review of the efficacy and safety of antiretroviral drugs against SARS, MERS or COVID-19: initial assessment. J Int AIDS Soc. 2020;23:e25489.

48. McCreary E, Pogue J. On behalf of the society of infectious diseases pharmacists. Coronavirus disease 2019 treatment: a review of early and emerging options. Open Forum Infect Dis. 2020;7:ofaa105.

49. Touret F, de Lamballerie X. Of chloroquine and COVID-19. Antiviral Res. 2020;177:104762.

50. Michot JM, Albiges L, Chaput N, Saada V, Pommeret F, Griscelli F, et al. Tocilizumab, an anti-IL6 receptor antibody, to treat COVID-19-related respiratory failure: a case report. Ann Oncol. 2020;1:300.

51. Feldmann M, Maini R, Woody J, Holgate ST, Winter G, Rowland M, et al. Trials of anti-tumour necrosis factor therapy for COVID-19 are urgently needed. Lancet. 2020;S0140-6736:30858-8.

52. McCullers JA. The co-pathogenesis of influenza viruses with bacteria in the lung. Nat Rev Microbiol. 2014;12:252-62.

53. Amanat F, Krammer F. SARS-CoV-2 vaccines: status report. Immunity. 2020;52:583-9.

54. Lazzerini M, Putoto G. COVID-19 in Italy: momentous decisions and many uncertainties. Lancet Glob Health. 2020;18:30110.

55. Legido-Quigley H, Mateos-García JT, Campos V, Gea-Sánchez M, Muntaner C, McKee M. The resilience of the Spanish health system against the COVID-19 pandemic. Lancet Public Health. 2020;18:30060.

56. Soriano V. Corral $O$. Keeping alive enterprises whereas embracing unprecedented COVID-19 restrictions. Ther Adv Infect Dis. 2020;7:1-2.

57. Flaxman S, Mishra S, Gandy A, Unwin JT, Coupland H, Mellan TA, et al. Estimating the Number of Infections and the Impact of Non-pharmaceutical Interventions on COVID-19 in 11 European Countries. Imperial College COVID-19 Response Team; 2020.

58. Black J, Bailey C, Przewrocka J, Dijkstra K, Swanton C. COVID-19: the case for health care worker screening to prevent hospital transmission. Lancet. 2020;16:S0140-6736:30917.

59. Xu S, Li Y. Beware of the second wave of COVID-19. Lancet. 2020;8:30845.

60. Tapper E, Asrani S. COVID-19 pandemic will have a long-lasting impact on the quality of cirrhosis care. J Hepatol. 2020;13:30217.

61. Soriano V, del Romero J. Rebound in sexually transmitted infections following the success of antiretrovirals for HIV/AIDS. AIDS Rev. 2018;20:187-204

62. Rosembaum $L$. The untold toll the pandemic's effects on patients without COVID-19. N Engl J Med. 2020;17:2009984.

63. El-Sadr W, Justman J. Africa in the path of COVID-19. N Engl J Med. 2020;1:2008193

64. Bryan C, Podolsky S. Sir William Osler (1849-1919) the uses of history and the singular beneficence of Medicine. N Engl J Med. 2019;381:2194-6.

65. Soriano V. Jérôme Lejeune passed away 25years ago. Hereditas. 2019;156:18.

66. Pellegrino ED. The internal morality of clinical medicine: a paradigm for the ethics of the helping and healing professions. J Med Philos. 2001; 26:559-79. 